\title{
THE COMPARATIVE ANATOMY OF THE NASAL TRACT AND THE FUNCTION OF THE SPERMACETI ORGAN IN THE PHYSETERIDAE (MAMMALIA, ODONTOCETI)
}

\author{
by \\ E. J. SCHENKKAN \& P. E. PURVES \\ Zoological Laboratory, University of Amsterdam, The Netherlands \\ British Museum (Natural History), London, Great Britain
}

\begin{abstract}
The nasal complex of Kogia has been compared with that of Physeter and shown to be homologous with that of less specialized ondotocetes.

The nasal complex of the Physeterids is structurally related to that of the Platanistics and Ziphioids.

The spermaceti orcan unique to the Physeteridae forms a part of the functional morphology of the right naris and is not a bilaterally symmetrical structure like the melon of other odontocetes.

Separation of the two nares in the Physeteridae is caused by the asymmetrical development of the spermaceti organ. In Kogia part of the musculature of the left naris actuates the opening of the right naris, a feature unique amongst the Mammalia.

The right naris is not used in external respiration but forms an air reservoir subservient to phonation at extreme depths.

The spermaceti organ assists in evacuation of the lungs prior to a deep dive.

The fat depots of the spermaceti organ in Physeter and the spermaceti organ and adipose cushion in Kogia may serve to absorb nitrogen at extreme pressure.

The air reservoirs could perform a useful hydrostatic function during the ascent from great depths.
\end{abstract}

\section{FOREWORD}

This paper forms part of a comprehensive study of the upper respiratory system in the suborder Odontoceti leading to a doctorate thesis, to be presented by the first author.

The general plan was to arrange the morphological characteristics of the "Blowhole" into a homologous series of increasing specialization from the primitive river-dolphins to the more highly specialized pelagic odontocetes.

It soon became obvious however, that the respiratory mechanism in the Physeteridae was so aberrant as to require special study in order to fit the arrangement into a hierarchical system. All the dissection, drawing and photography were carried out by the first author, and the interpretation of the results, phylogenetically and functionally was the result of collaboration between both authors, with many conclusions being arrived at independently by each author.

\section{INTRODUCTION}

The anatomy of the blowhole of Kogia has been described by Benham (1901), Danois (1910), Kernan \& von Schulte (1918). The last two authors have given the best account and their drawings demonstrate the various structures with great clarity. The nasal tract of Physeter has been described by Pouchet \& Beauregard (1885), Beddard (1915, 1919), Raven \& Gregory (1933), and of these, the last named paper is the most useful. However, excepting in respect to the deliniation of the entrance to the right nasal passage, none of the above mentioned authors have attempted to homologise the apparently aberrant nasal structures of the Physeteridae with those of the more conventional odontocetes. One of the more frequently occurring statements is that the spermaceti organ is the equivalent of the globular mass of adipose tissue, or melon, that is to be found on the forehead of most dolphins, porpoises and small odontocete whales.

Since it is the purpose of this paper to identify all the nasal structures of the Physeteridae with those of the less specialized odontocetes, it is necessary to reiterate briefly observations that have been published in detail by Tyson (1680), Hunter 


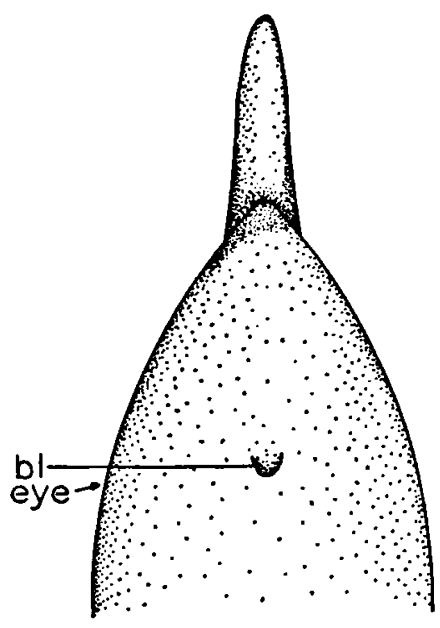

A

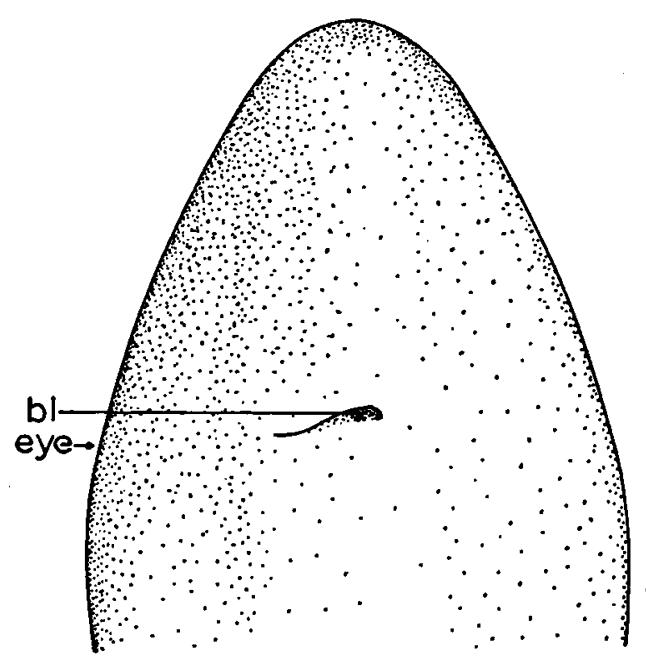

B

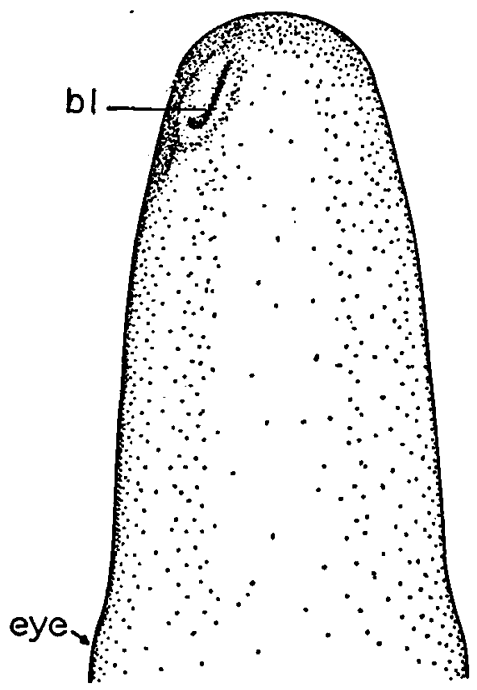

C

Fig. 1. Diagrams showing the position and shape of the blowhole in various odontocetes. A, a conventional odon tocete; B, Kogia; C, Physeter.

(1787), Murie (1873), Rawitz (1900), Gruhl (1911), Lawrence \& Schevill (1956), Purves (1966), and Schenkkan (1971).

The nasal orifice or blowhole (BL) of the majority of odontocetes (fig. 1,A) consists of a small crescentic opening situated on the top of the head and slightly displaced to the left. Immediately below the blowhole, the orifice widens slightly to form the "vestibule", (fig. 9:V) the lumen of which in the resting state, is almost filled by the anterior and posterior lips of the blowhole. On each side of the vestibule a longitudinal aperture leads into a large lateral diverticulum or "vestibular sac" (SV), the dorsal and ventral linings of which may be complexly folded as in the Phocoenidae or relatively simple as in the Platanistidae.

Deep to the vestibular sacs, another pair of lateral diverticula surround each side of the nasal canal in approximately semi-circular form (SN). The lumen of these "nasofrontal sacs" may be relatively large as in Phocoena and Lagenorhynchus or narrow and tubular as in the majority of the Delphinidae. The name "tubular sac" has been assigned to these sacs by Lawrence \& Schevill (loc. cit.). The anterior component of the nasofrontal sac is absent in the Platanistidae and Hyperoodon and present on the right side only in Mesoplodon. At the lateral extremity of the caudal component of each nasofrontal sac there is a small blind diverticulum directed rostroven- trally which has been variously described as "Blindsack" (Gruhl, 1911), "connecting sac" (Lawrence \& Schevill, 1956) and "accessory sac" (SA) (Schenkkan, 1971).

The lips of the blowhole, the vestibular, nasofrontal and accessory sacs are controlled by fascial insertions of the maxillonasalis and maxillolabialis muscles which are greatly enlarged in comparison with those of most terrestrial mammals and originate on the expanded and squamated maxillary bones.

The upper part of the nares is occluded by a pair of bulbous "nasal plugs" (NP) that can more accurately be described as caudoventral convexities of the rostral wall of the nares. These plugs can apparently be drawn partly rostrad out of the nares by "nasal plug muscles" which have a characteristic appearance, the red fibres being relatively short and intercalated between numerous strands of white fibrous tissue which originate partly on the dorsal aspect of a pair of "premaxillary sacs" and the premaxillary bones but mainly from the mass of adipose tissue commonly called the "melon". The premaxillary sacs are diverticula of the lowest part of the upper nares and occupy the dorsal aspect of the smooth, expanded caudal extremities of the premaxillary bones. The premaxillary sacs seem generally to be indirectly proportional in size to that of the nasofrontal complex being relatively minute in the Platanistidae and Phocoenidae and large in the 
more highly specialised Delphinidae. The melon, which is often regarded as a structure "de novo", peculiar to cetaceans can be seen on careful examination of its structure and innervation to be merely an adipose hypertrophy of the maxillolabialis and maxillonasalis muscles.

Throughout the entire suborder of Odontoceti the whole assembly of muscles and airsacs is more or less asymmetrically developed, the components of the right side being larger than those of the left. This asymmetry is reflected in the degree of development of bones on the dorsal aspect of the skull, with the single exception that the left bony naris is frequently larger than the right. Purves (1966) has associated this asymmetry with the loss of olfactory organs and the dorsal displacement of the blowhole.

In the Physeteridae this asymmetry has an extreme state of development, the lumen of the right naris being relatively small whilst that of the left is greatly enlarged, being up to seven times the diameter of the right. The whole airsac complex of the right side is greatly hypertrophied whilst that of the left is all but absent.
An entirely new structure, the spermaceti organ, which may have no homologue in other odontocetes has developed between the two nares bringing about gross distortion of the upper narial complex. It is perhaps for this reason that authors have been cautious to assign to the Physeteridae the anatomical nomenclature of other odontocetes.

\section{MATERIAL AND METHODS}

The material for the present study consisted of the head of a specimen of Kogia simus (Owen, 1866) which had been loaned for dissection to the British Museum (Natural History) by Dr. P. B. Best of South African Museum in Cape Town and two heads of Kogia breviceps (De Blainville, 1838) also obtained for dissection by the courtesy of Drs. P. J. H. van Bree of the Institute of Taxonomic Zoology of the University of Amsterdam. The Amsterdam specimens are registered ZMA 14.817 and ZMA 15.241. All specimens had been deepfrozen and were dissected after being thawed out. Both specimens of Kogia

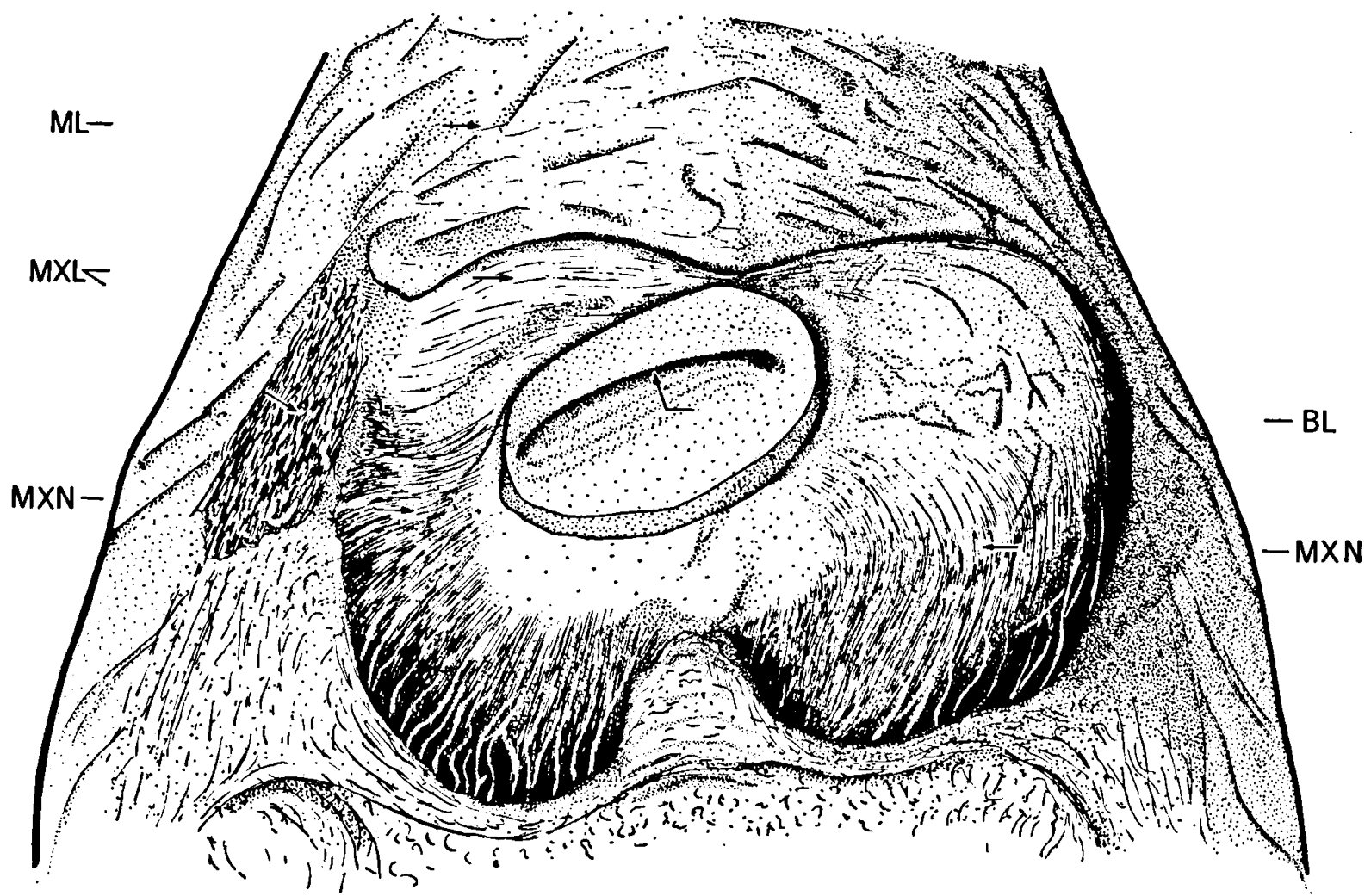

Fig. 2. Dissection showing the blowhole and nasal muscle complex of Kogia breviceps. The bilateral asymmetry of the muscles should be noted. For abbreviations, see page 111 . 
breviceps were stranded on the coast of New Zealand near Napier and were collected by $\mathrm{Mr}$. Frank D. Robson and frozen in fresh condition. The smaller Kogia simus was sent from South Africa. Concurrently with the dissection of $K$. simus the preserved head of a $150 \mathrm{~cm}$ foetus of Physeter macrocephalus Linnaeus, 1758 was also examined for comparison with Kogia. During all the dissections samples were taken for histological examination. As it is virtually impossible to delineate by dissection the ramifications of the complicated nasal tract of Kogia, a silicone rubber cast of a specimen of $K$. breviceps was made in the Zoological Laboratory of the University of Amsterdam and this afforded the opportunity to measure the dimensions of the various parts.

\section{RESULTS}

The blowhole and vestibular sacs

The blowhole was situated more to the left in $K$. simus than in $K$. breviceps; it consisted of a shallowly crescentic aperture with the convexity facing posteromesially and thus differed from that of most odontocetes in which the concavity faces rostrad with its long axis at approximately right angles to that of the body (fig. 2).

The anterior lip of the blowhole was crescentic in shape with its concavity facing caudally and in its resting position, overlapped the posterior lip contrary to the condition found in other odontocetes. Immediately below the crescentic nasal orifice there was a narrow space which may be termed the "vestibule" but this was almost totally occupied by the thick posterior lip of the blowhole. The anterior wall of the vestibule had a convexly swollen appearance and was referred to by Benham (1901) and Danois (1910) as the "floor" of the vestibule but this was not found in the foetus of $K$. breviceps by Kernan \& von Schulte (1918). In the extreme ventromesial corner of the vestibule (fig. 3) there was a caudal

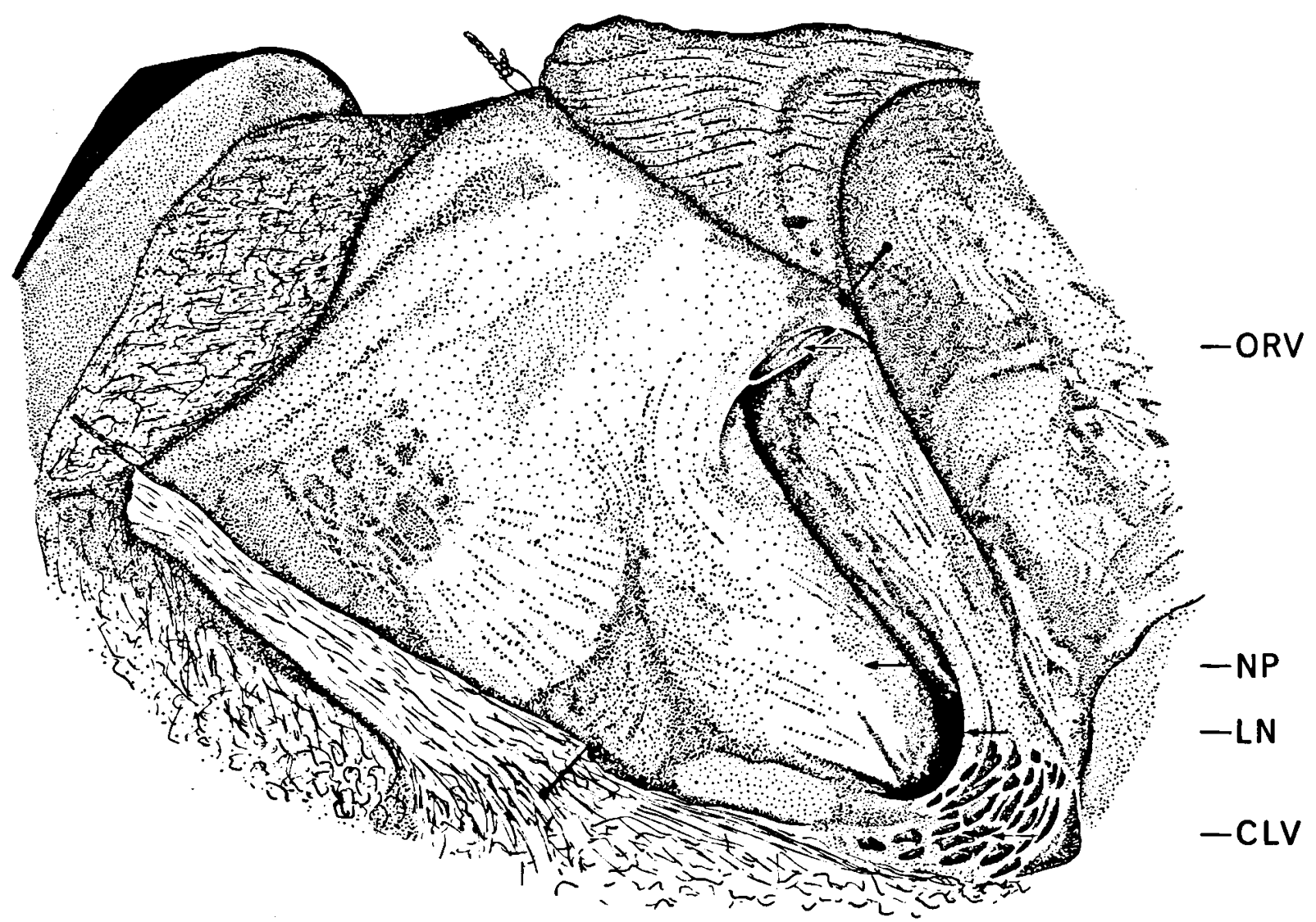

Fig. 3. Dissection of the blowhole of Kogia breviceps. The rostral wall of the vestibule has been reflected rostrally to expose the orifice of the right vestibular sac, the left nasal plug, the left naris and the crypts of the left vestibular sac. The orifice of the right vestibular sac has been dilated by traction on the rostral lip of the blowhole. For abbreviations, see page 111 . 
dilatation of the vestibule which led into a number of small anastomosing pouches (fig. 3: CLV). This dilatation together with the pouches was considered to be the left "vestibular sac" its volume being controlled by elements of the maxillonasalis and maxillolabialis muscles (fig. $2: \mathrm{MXN}$, MXL). In the extreme mesial corner of the vestibule there was a horizontally orientated membrane passing from the mesial axis to the dorsal wall of the floor of the vestibule and in its free caudal edge there was a horizontal slitlike opening measuring $2.5 \mathrm{~cm}$ in $K$. breviceps and about $1 \mathrm{~cm}$ in $K$. simus (tig. 3: ORV). From this slit which had the appearance of a one-way valve giving access only to the exterior, a short canal led into a capacious, approximately circular sac, measuring $11 \mathrm{~cm}$ in diameter in $K$. breviceps and resembling in its concavoconvexity the head of a mushroom. On the posterior and ventral peri- phery of this sac there were numerous apertures leading into long, moniliform anastomosing diverticula. Those on the posterior periphery passed at first laterally then rostrally in an arcuate course and then mesially and dorsally in a similarly curved manner. Those on the ventral periphery passed at first laterally; they then turned rostrally and finally dorsally and caudally to merge with those from the posterior periphery.

The whole assembly formed a large domeshaped mass of air pouches (fig. 4) measuring 17.5 by $12 \mathrm{~cm}$ in $K$. breviceps which enclosed within its boundaries a large ovoid cushion of mainly adipose tissue (fig. 5: AC). Numerous red muscular strands originating from the maxillonasalis muscle passed through the interstices between the pouches and were inserted into the posterior margin of the adipose cushion. Other, more tendinous slips and bloodvessels passed

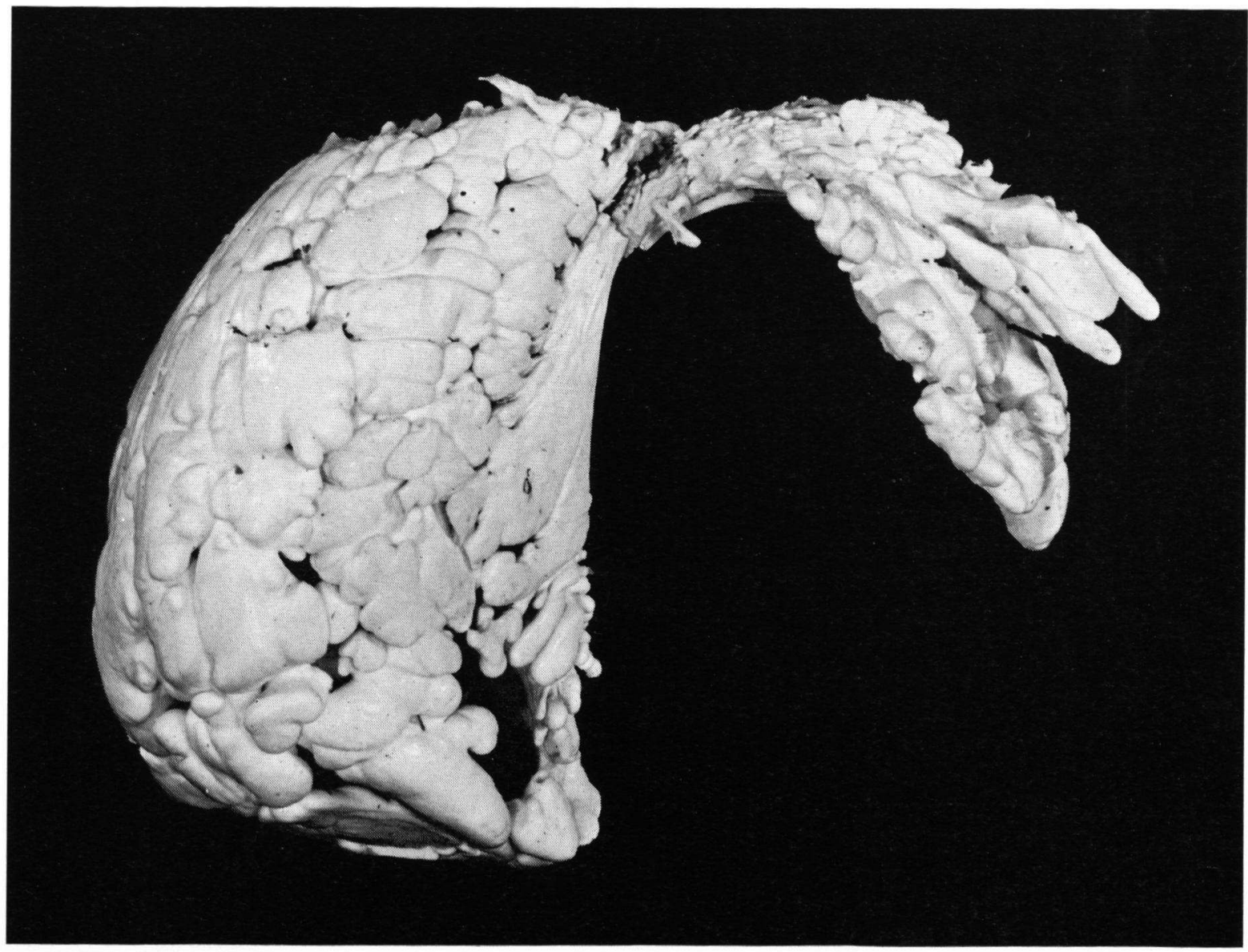

Fig. 4. Rostral aspect of a silicone rubber cast of the right vestibular sac of Kogia breviceps. (Photo: $\mathrm{S}$. van Mechelen). 


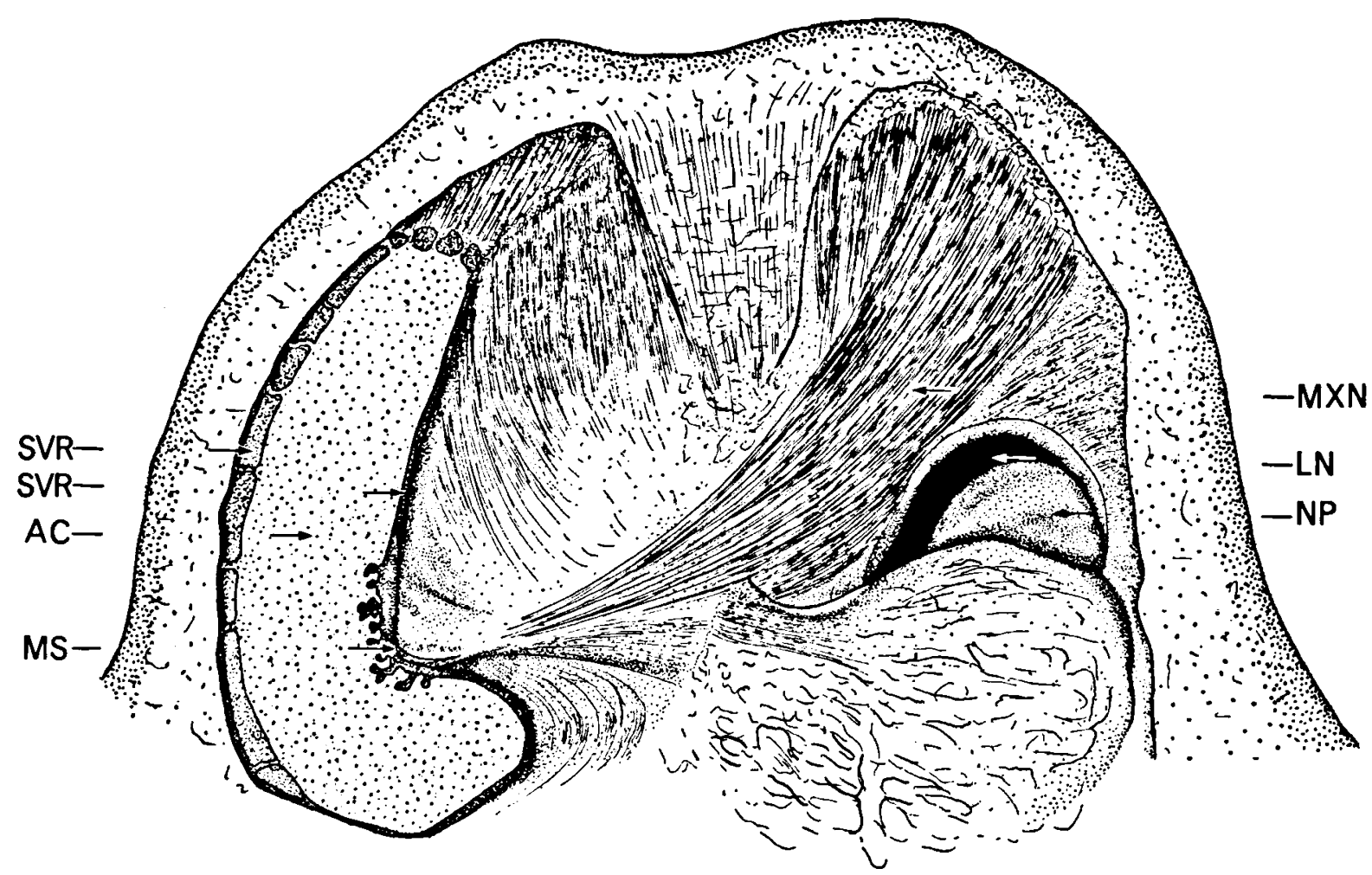

Fig. 5. Dissection of the nasal complex of Kogia breviceps deep to the vestibular sacs and superficial nasal muscles showing the ventral half of the adipose cushion, the "museau de singe", the aberrant sheet of the left maxillonasalis muscle, the left narial aperture and its nasal plug. For abbreviations, see page 111.

through all the small spaces between the pouches and were inserted into the cushion over its entire upper surface.

Approximately in the centre of the floor of the undifferentiated concavoconvex air sac first described above, we found the slitlike opening into the right nasal canal (fig. 5: MS). Opposite this slit, on the dorsal wall of the air sac which formed the base of the adipose cushion, there were numerous folds in the mucous membrane running in a curved course on both sides of the axis of the slit. From these there was a small circular group of crypts leading into the ventral aspect of the fatty cushion (fig. 6).

Near the entrance to the undifferentiated first cavity, a relatively small diverticulum led into another system of pouches similar to, but not as extensive as those previously described (fig. 4). These passed dorsally and mesially in front of the vestibule to extend beyond the mesial axis of the head to the left hand side. They then turned ventrally in an arcuate course to penetrate deeply into the body of the left maxillolabialis muscle; their distal extremity being almost contiguous with the insertion of that muscle on the maxilla.

The whole assembly of air cavities described above was considered because of its relationship to the vestibule and right nasal canal to be homologous with the right vestibular sac (fig. 9: SVR) in other odontocetes, its volume being controlled by elements of the right maxillonasalis and maxillolabialis muscles (fig. 2: MXN, MXL).

\section{The nasal passages}

Starting again at the vestibule, the convex floor bent ventrally to the entrance of the left nasal passage which took the form of a sigmoid opening in the ventral margin of the vestibule. The curved floor of the vestibule passed without differentiation into the rostral wall of the left nasal canal, which was strongly convex in conformity with the former. With this convex configuration the rostral wall nearly completely filled the lumen of the left nasal canal which sloped further ven- 


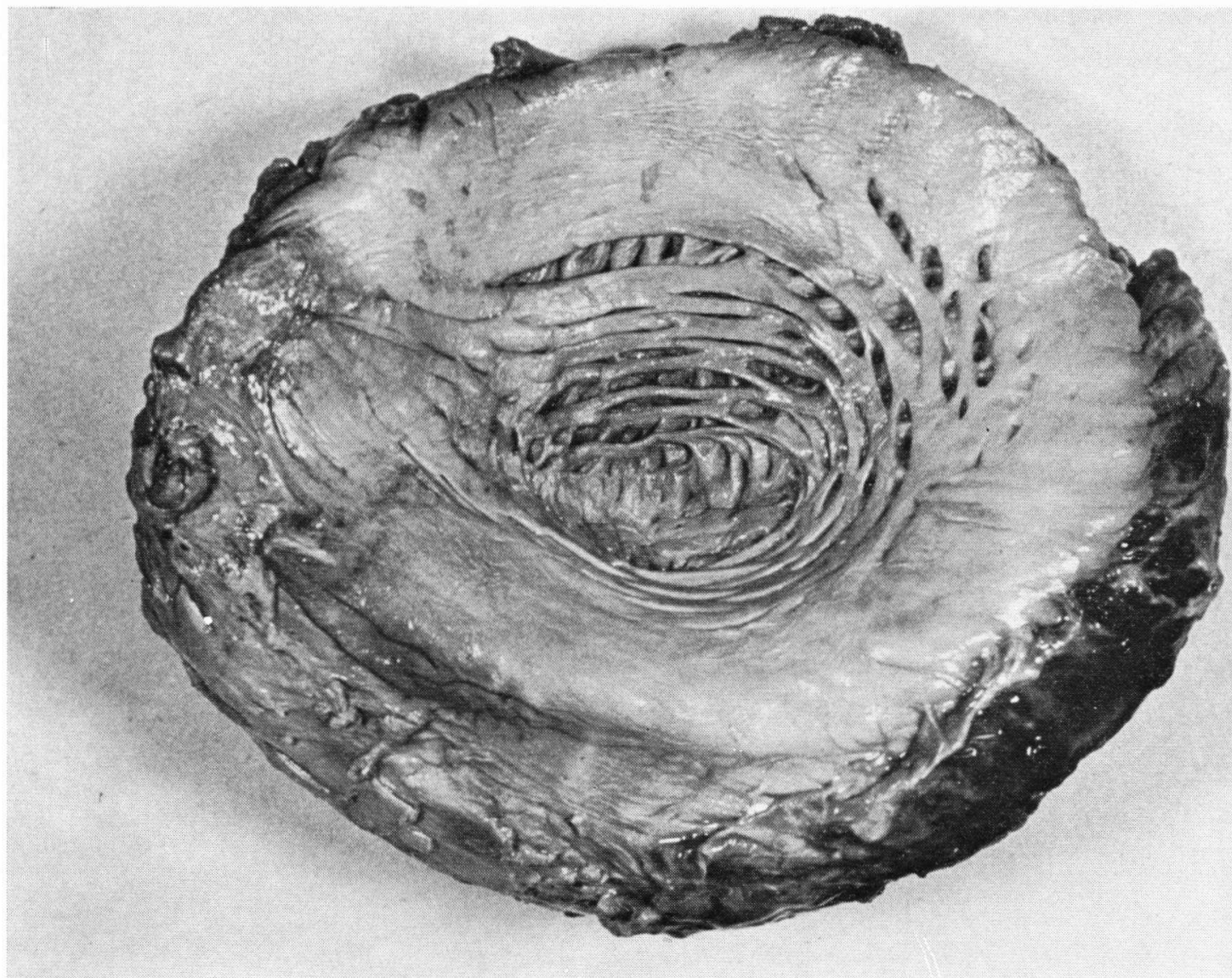

Fig. 6. Photograph of the concave ventral aspect of the adipose cushion in Kogia breviceps showing crypts and caudal insertions of elements of the maxillonasalis muscles:

trad to the bony naris (fig. 3: LN). This convex, rostral wall of the naris terminated in the left nasopalatine canal as a large bulbous structure which in the resting state occluded the canal. Below the level of the bulb a small invagination of the rostral wall of the nasal canal formed a small "premaxillary sac".

Examination of the structure of this rostral wall of the left naris showed that it consisted of typical "nasal plug" tissue like that described above for other odontocetes. It consisted of a mass of short red muscle fibres intercalated between strands of white fibres, the more ventral mass of which originated on the premaxillary bones whilst the more dorsal fibres penetrated the melon. We therefore considered the whole length (14 $\mathrm{cm}$ in $K$. breviceps) of this convex rostral wall of the nasal passage including the bulbous termination to be the homologue of the left "nasal plug" of more conventional odontocetes (NP).
The small premaxillary sac, which allowed the nasal plug to be pulled out of the nasopalatine canal, is also homologous with the left premaxillary sac of other odontocetes. No other diverticulum such as a nasofrontal sac could be found. The entrance to the left nasal canal and the entire posterior wall of the naris were subject to traction from the deeper elements of the maxillonasalis muscle which originated in the concavity of the left maxillary bone.

At the apex of the convex mesial aspect of the floor of the right vestibular sac, there was a small transverse slit lying horizontally at right angles to the mesial axis of the head. This structure was the homologue of that which Pouchet \& Beauregard (1885) referred to in Physeter as the "museau de singe". As will be demonstrated later, it also forms the homologue of the external lips of the right naris (fig. 9: MS) as found in the other odontocetes. These lips fitted exactly 


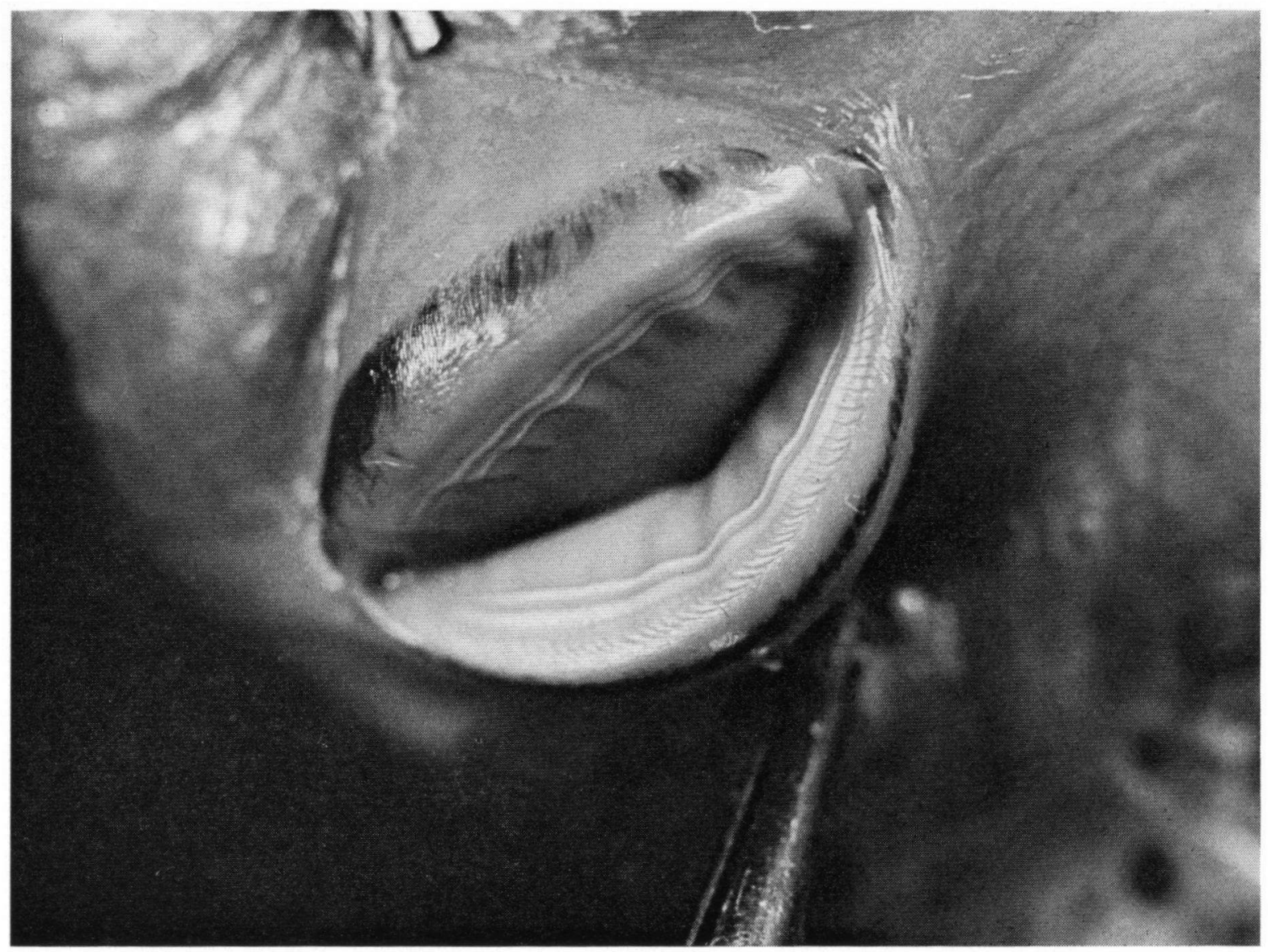

Fig. 7. Photograph of the lips of the "museau de singe" of the right naris. The lips have been drawn apart to show the structure of the interior walls.

into the concave central base of the large adipose cushion previously described. The lips of the "museau de singe" were peripherally streaked with black pigmentation and the interior margins, normally contiguous, were marked by two narrow bands of white fibrous tissue lying parallel with the free edges of the aperture. The edges of the lips were also marked by small grooves presenting a scalloped appearance (fig. 7).

When the lips of the blowhole and the vestibule are removed from the head of a dolphin or porpoise, the entrances to the two nasal canals can be seen clearly. These consist of opposed anterior and posterior lips which are usually covered by black epithelium and of a shape characteristic of the species. The opposing surfaces of the lips are sculptured to fit each other exactly with one or more horizontal ridges and grooves which frequently present a scalloped appearance strikingly similar to that found on the lips of the "museau de singe" in Kogia. The presence of vestiges of black pigmentation in this area helps to confirm our opinion that the "museau de singe" is the true homologue of the lips of the right naris in conventional odontocetes. From the left half of the lumen of the "museau de singe" a small, caudorostrally flattened canal $1.5 \mathrm{~cm}$ wide, led at first in a slighty mesial direction and then curved caudolaterally to the small right nasopalatine canal (fig. 9, E: RN). The anterior wall of the nasal passage was slightly convex and on its rostral aspect was a strip of nasal plug muscle tissue which increased in volume and width in a ventral direction. The convexity of the anterior wall of the nasal passage terminated in the nasopalatine canal where it could completely occlude the lumen. No premaxillary sac could be traced. Because of its shape and relationship to the "nasal plug muscle" tissue we deemed the convexity of the anterior wall of the 


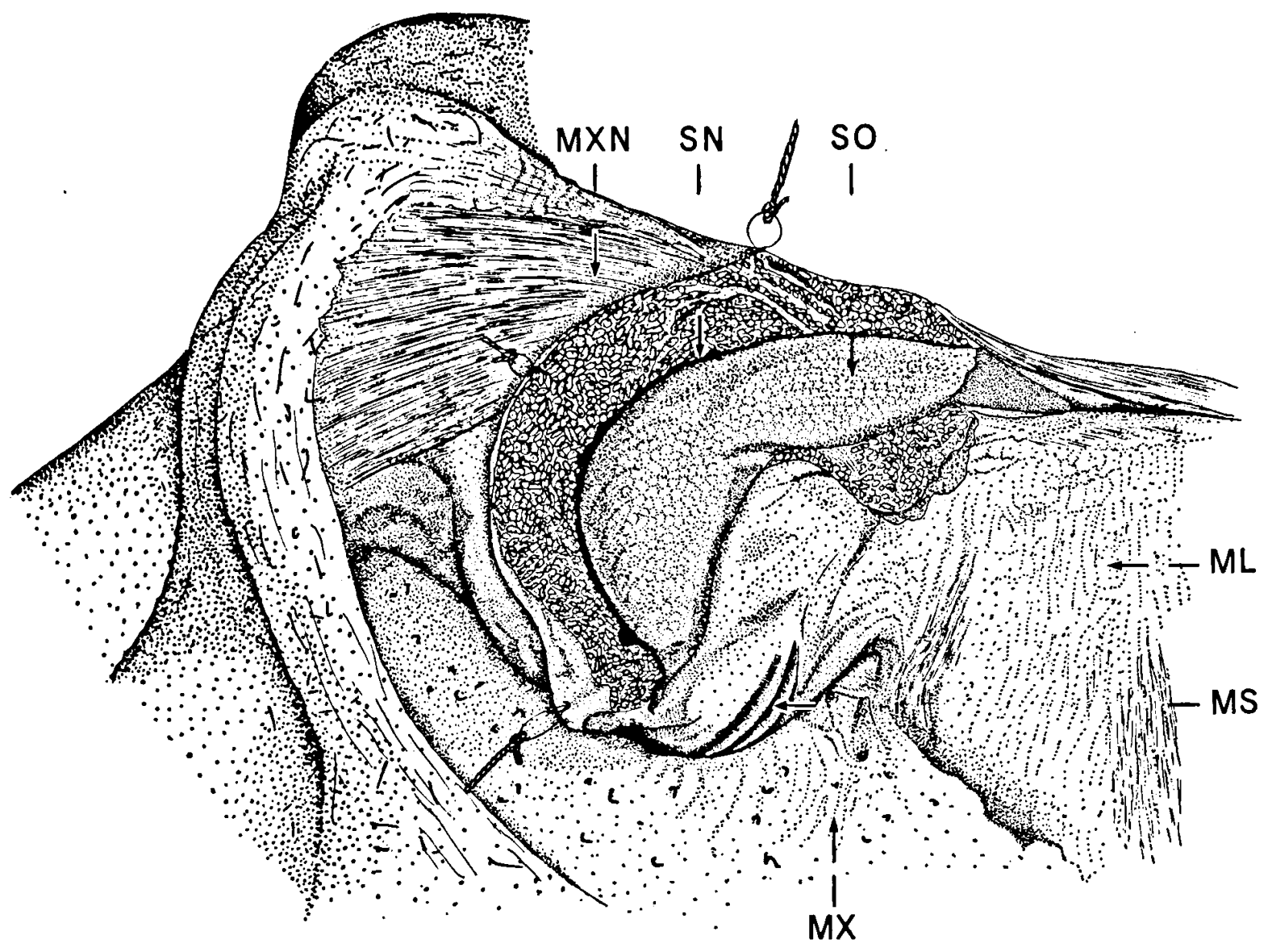

Fig. 8. Dissection of the right nasofrontal sac in Kogia breviceps showing the papillated wall reflected caudally from the spermaceti organ. For abbreviations, see page 111.

right nasal canal to be the homologue of the right nasal plug (RN) of other odontocetes. The aperture of the "museau de singe" could be dilated by traction on the deeper elements of the right nasolabialis muscle which originated in the concavity of the right maxillary bone and to some extent by traction on an aberrant slip of muscle from the left maxilla (fig. 5: MXN). Just before the right nasal passage entered the nasopalatine canal its posterior wall was discontinuous, giving entrance to a large dorsally directed diverticulum, measuring $10 \mathrm{~cm}$ by $10 \mathrm{~cm}$, the caudal lining of which was set with numerous small papillae (fig. 8). The caudal wall of this sac was closely applied to a concavity on the expanded, external aspect of the caudodorsal extremity of the right premaxilla, whilst the lower margin of the rostral wall gave access to the right nasal canal. Benham, Danois, Kernan \& von Schulte referred to this chamber as the lower respiratory or in- ferior spiracular sac but because of the anatomical relationships described above we consider it to be the homologue of the caudal part of the nasofrontal sac of other odontocetes.

This homology is particularly well seen with reference to the Ziphioids in which the caudal nasofrontal sac is in close relationship to the expanded anterior aspect of the premaxilla.

\section{The spermaceti organ}

It was observed that in Kogia the right and the left nasal passages were widely separated and not contiguous as in other small odontocetes. This arrangement is entirely due to the interposition of the spermaceti organ now to be described.

When the dorsal wall of the nasofrontal sac was dissected, the sac was seen partially to envelop a large, pyriform body (fig. 8: SO) present- 


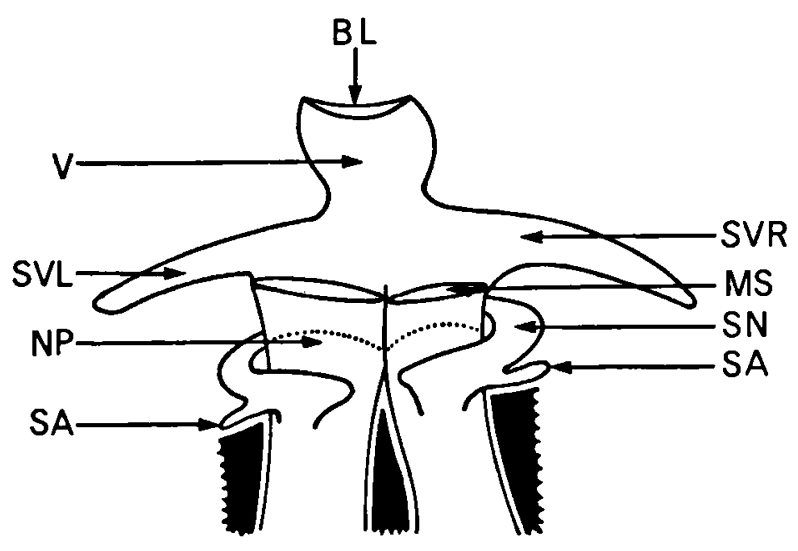

A

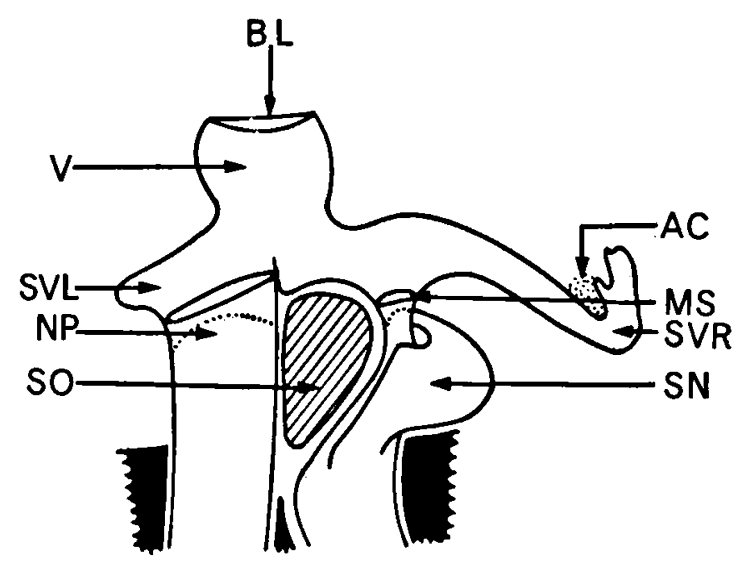

C

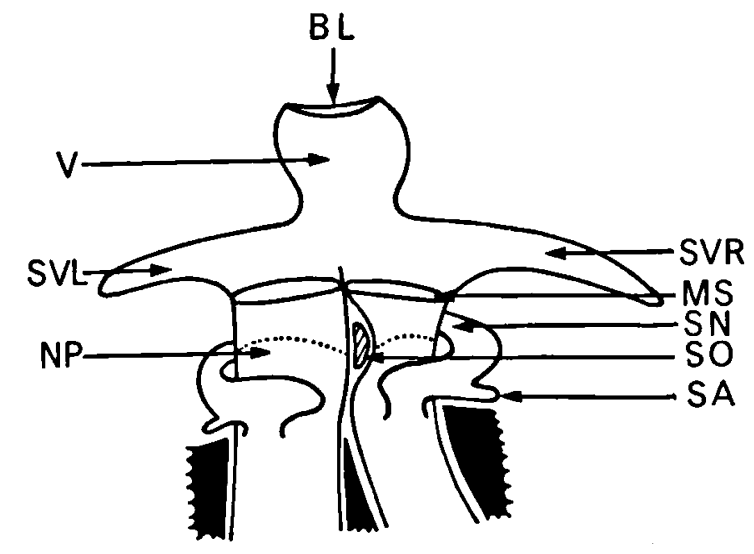

B

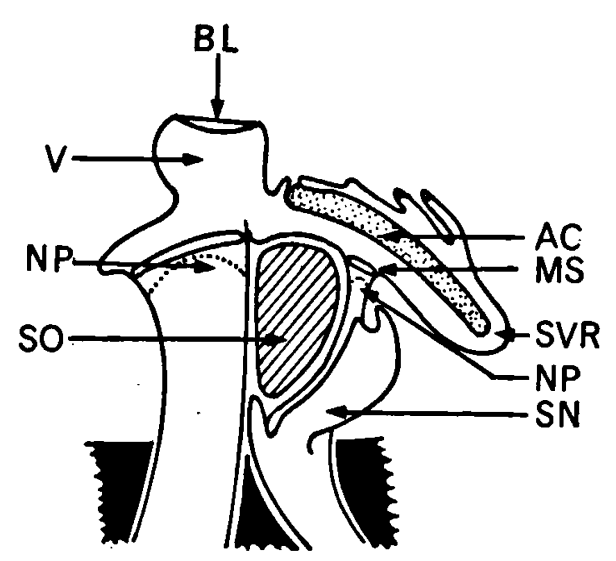

D

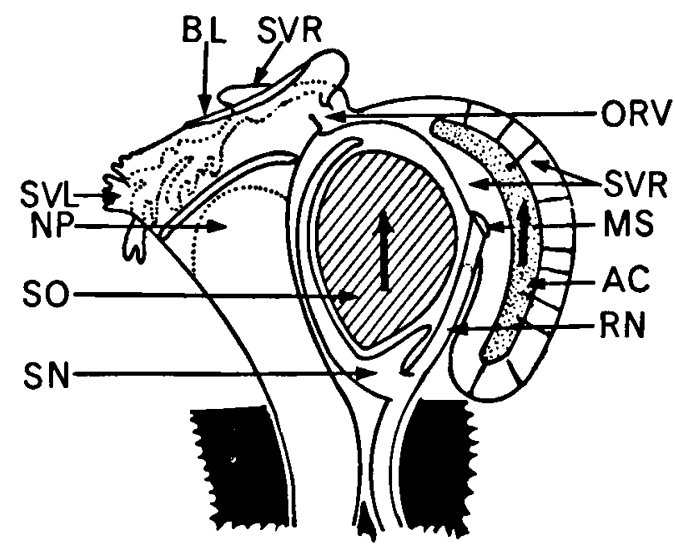

$E$

Fig. 9. Series of schematic diagrams showing the development of the spermaceti organ in odontocetes. C and D are hypothetical intermediate stages between typical odontocetes (A), Cephalorhynchus hectori (B), and Kogia (E). For abbreviations, see page 111 . 
ing a smooth, reddish coloured exterior aspect. The hilus of the body was folded posterolaterally so that its apex pointed to the right corner of the "museau de singe". The smooth external skin of the spermaceti organ which also formed the rostral wall of the nasofrontal sac consisted of a mucous membrane overlying a thick layer of fibrous tissue. Inside the membranous outer covering there was a bulbous mass of adipose tissue.

In its relationship to the other structures of the head, the spermaceti organ is in no respect homologous with the "melon" of other odontocetes as had been postulated by Raven \& Gregory (1933). The spermaceti organ is situated posterior to the nasal tract and not anterior to it as does the melon of other odontocetes. It is also contiguous with the caudal part of the nasofrontal sac, whilst the melon is separated from it by the whole nasal complex. It is clear that the spermaceti organ is an adventitious structure developed asymmetrically within the fibrocartilaginous nasal septum. We can conceive it starting as a small pisiform body situated within the septum on right hand side of the cartilage, indeed such a body has been observed in Cephalorhynchus hectori (van Beneden, 1881). This body becomes gradually enlarged, particularly on the right side bringing about gradual separation of the nares (fig. 9, AE). Simultaneously the nasofrontal and vestibular sacs of the right side become correspondingly enlarged whilst those of the left become greatly reduced. Finally in the Physeteridae the two nasal passages have become widely separated and the nasofrontal and vestibular sacs of the left side have disappeared altogether.

Evidence in support of this hypothesis could be seen in the fact that during the dextrad separation of the right naris from the left in Kogia the former had apparently "parasitised" some of the latters musculature, thus there was a substantial slip of muscle that orgininated on the right

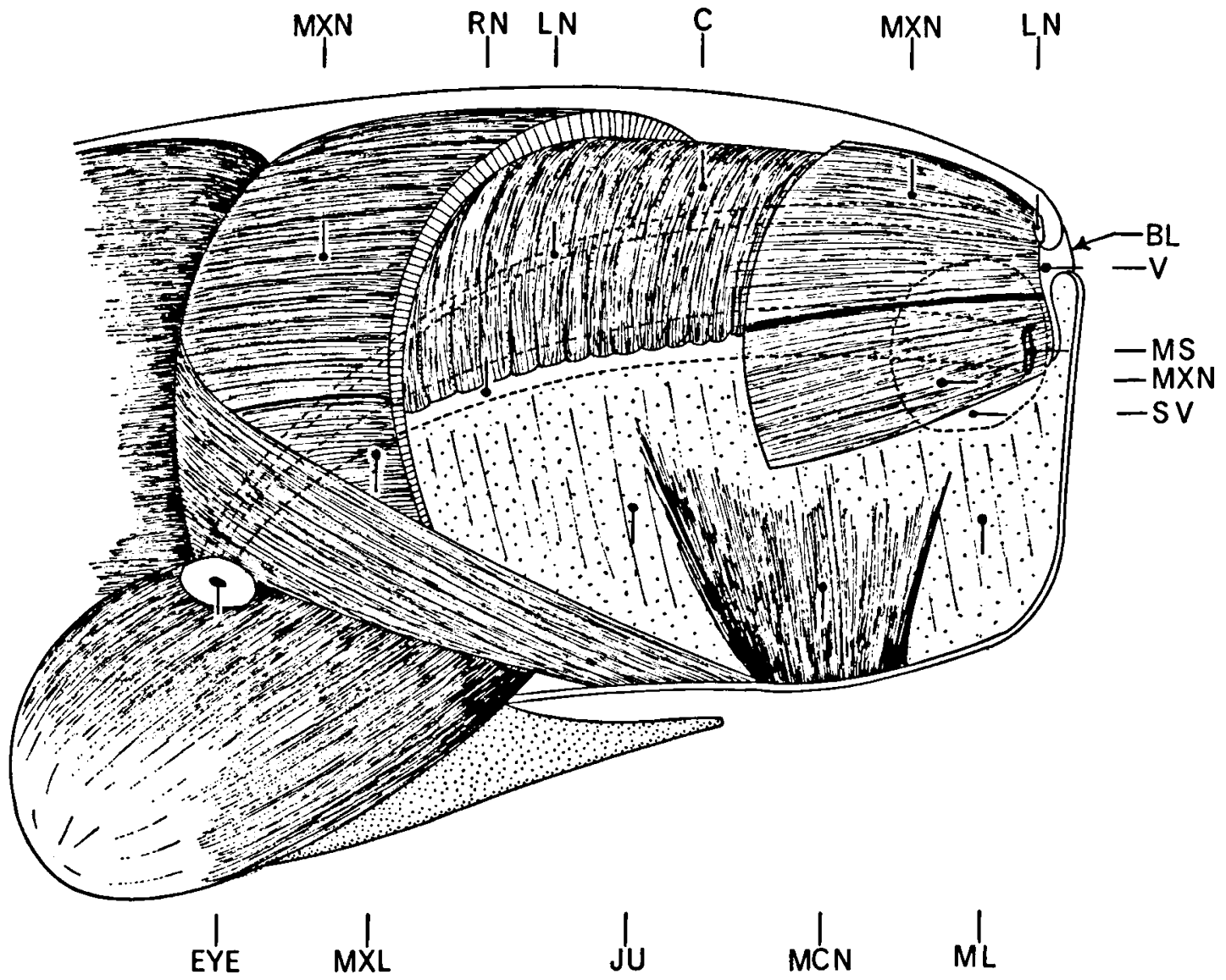

Fig. 10. Diagram showing arrangement of nasal muscles in a $150 \mathrm{~cm}$ foetus of Physeter macrocephalus. For abbreviations, see page 111 . 


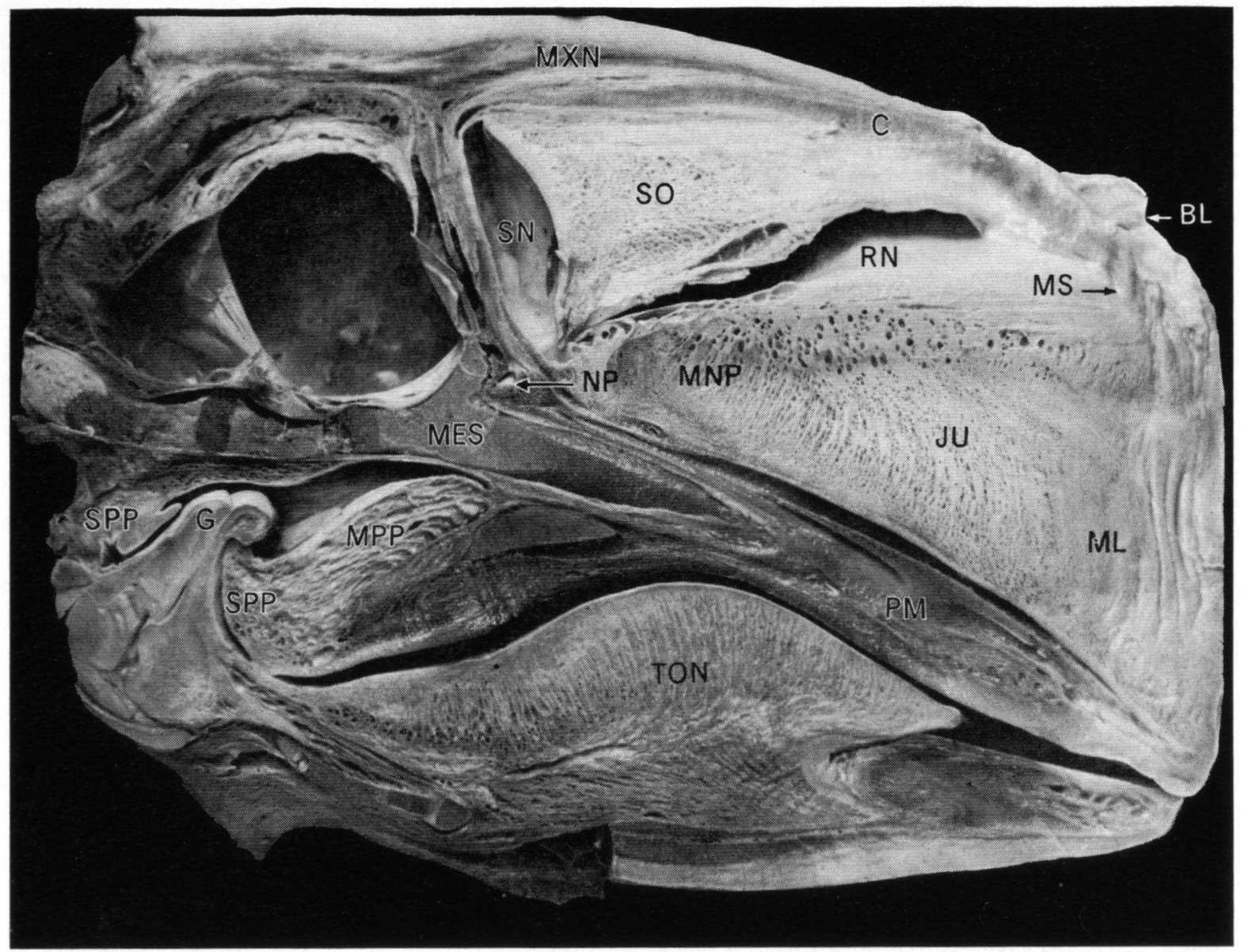

Fig. 11. Photograph of a sagittal section through the head of a $150 \mathrm{~cm}$ foetus of Physeter macrocephalus. For abbreviations, see page 111 .

maxilla but crossed completely over the median line to be inserted into the right hand corner of the left nasal aperture or "museau de singe" (fig. 5: MXN).

Additional evidence could be found in the fact that a thin sheet of muscle, which originated on the median right maxillary crest, wrapped round the rostral aspect of the spermaceti organ to be inserted into the rostral wall of the right naris along with the right nasal plug musculature and was undoubtedly an aberrant part of the latter.

Pouchet \& Beauregard and Raven \& Gregory (loc. cit.) have described the anatomy of the head of Physeter but as the general organization is so different from that of the majority of odontocetes they have not attempted to homologize the various structures with those of the more conventional types. Raven \& Gregory have, mistakenly we think, considered the spermaceti organ to be homologous with the "melon" of Monodon. The size and position of the spermaceti organ in Kogia, the structure of the skull in the latter genus and in fossil Physeterids, the observation of the position of the blowhole in very young embryos lead us to believe that in the ancestral form of Physeter the blowhole was situated more nearly on top of the head as in Kogia and other odontocetes. Its position at the anterior extremity of the head in the recent form we believe to be entirely due to the enormous enlargement and rostrad development of the spermaceti organ.

As evidence in support of this hypothesis we can draw attention to the following anatomical peculiarities. The whole maxillonasalis and maxillolabialis muscle complex originates on the maxillary crest of the skull posteriorly to the blowhole and passes forward on the dorsal and lateral aspects of the rostrum to terminate at various insertions in the blowhole (fig. 10). In most odontocetes the maxillolabialis originates on the max- 
illary bones anterior to the blowhole and passes posteriorly and mesially towards the latter. The left and right nares (LN, RN) are also greatly elongated rostrally and are widely separated from each other at the blowhole as in Kogia. Perhaps the most striking evidence in support of the hypothesis is to be seen in the constitution of the walls of the nares. On the left side there are strong insertions of elements of the maxillonasalis muscle on the dorsal, concave wall of the naris throughout its length and on the ventral, strongly convex wall is inserted the typical nasal plug muscle tissue.

On the right side the insertions of the right maxillonasalis are not very strong, the muscle fibres of this side lying almost parallel with the dorsal wall of the naris. The red muscle elements of the right nasal plug muscle are considerably reduced in number on the ventral wall of the naris and apparently also reduced in function. However, on close examination it seems that practically the whole of the fibrous mass of adipose tissue commonly referred to as the "junk" (figs. 10, 11) appears to be constituted of hypertrophied nasal plug tissue with strong bands of white fibrous tissue passing vertically into the dorsal aspect of the rostrum. The "melon" if present at all, is confined to the small area of the "junk" which protrudes beyond the bony rostrum.

Dilation of the blowhole and left naris is affected through insertions of the left maxillonasalis and left nasolabialis showing that the latter structure is predominantly of left narial origin as it is in Kogia. The insertions of right maxillonasalis and right maxillolabialis act on the posterior and anterior lips of the "museau de singe" respectively showing that this structure is of right narial origin and in fact constitutes

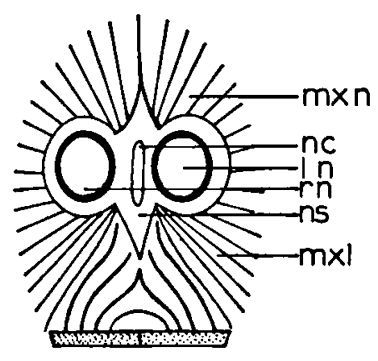

A

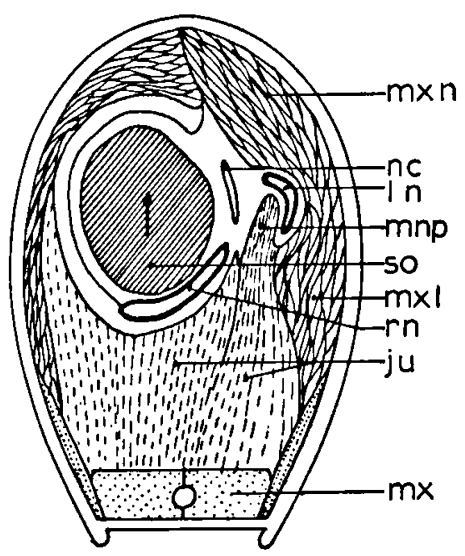

D

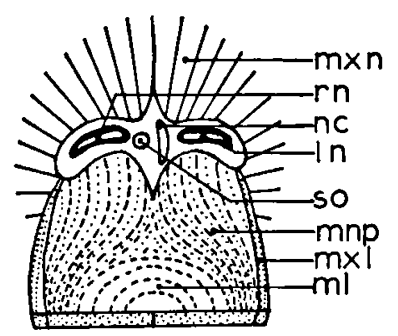

B

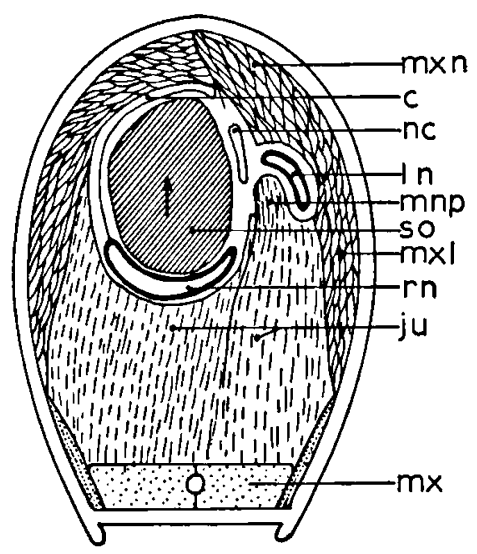

E

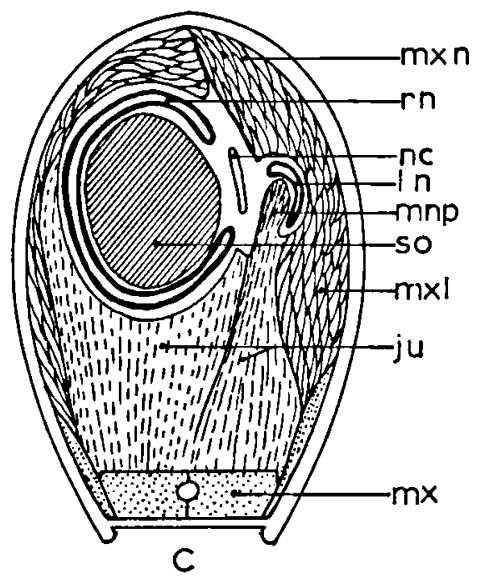

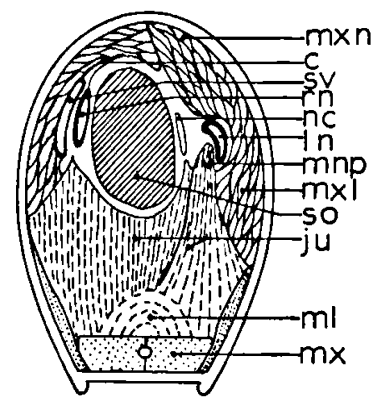

$\mathrm{F}$

Fig. 12. Schematic drawings showing the development of the spermaceti organ and nasal complex of Physeter from the terrestrial mammal and conventional odontocete. For abbreviations, see page 111. 
the lips of the right naris as in Kogia. There appear to be no muscies acting to dilate the vestibular aperture of the right naris and its form is that of a one-way valve opening outwards like that of the slit-like aperture in Kogia, possibly indicating that air does not normally enter by this route.

The vestibular aperture of the right naris leads immediately into a large, right vestibular sac as in Kogia but on the left side the vestibular sac is absent. It was seen that in Kogia the left vestibular sac was rudimentary.

As in Kogia the spermaceti organ of Physeter is a structure entirely associated with the right naris and appears to have been developed within the right wall of the nasal septum in the manner shown in diagrams $A$ to $F$ (fig. 12). A shows the nostrils of a hypothetical terrestrial mammal with the nasal muscles attached. B shows the arrangement in a hypothetical odontocete cetacean, demonstrating the morphological origin of the nasal plugs and nasal plug muscles. The site of a hypothetical, incipient spermaceti organ is shown on the right of the septal cartilage. $C$ shows a cross-section of the head in a developmental stage of Physeter. The spermaceti organ has become greatly enlarged with consequent distension and invagination of the right naris. In the cross-sections of the 1 metre foetus shown in $D, E$, and $F$, the mucous lining of the right naris has regressed differentially so that the outer covering of the spermaceti organ consists of a double layer of fibrous tissue which was once the supporting laminar of the mucous lining of the naris. In the foetus these two layers are easily separable but in the adult form a thick fibrous coat generally referred to as the "case" of the spermaceti organ. It will be seen that the configuration and position of the lumen of the right naris varies with the point of cross-section of the head, a fact which has considerable functional significance. The relationship of the vestibular sac to the right naris is shown in fig. 12: F. It will be seen that the spermaceti organ and right nasal plug come to occupy the major part of the rostral tissue. In the adult both of these organs become medially placed with respect to the rostrum with the consequence that the nasofrontal sac becomes correspondingly enlarged and symmetrically disposed about the central axis of the skull as in Kogia. This fact has an important bearing on hydrostatic stability at depth.

The total absence of the rostral part of the nasofrontal sac in both Kogia and Physeter recalls the condition found in the Platanistidae. A further similarity between the Physeteridae and the Platanistidae can be seen in the degree of the development of the right vestibular sac in Kogia, Pontoporia and Inia. In these three genera the right sac is considerably larger than that of the left side and an extension crosses the midline in front of the blowhole to terminate on the left side of the head. This latter arrangement is also of hydrostatic importance at the surface and at medium depths. The partial atrophy of the left vestibular sac has to be compensated for by a sinistrad development of the right vestibular sac in order to re-establish hydrostatic stability. The distribution of air cavities in the head of odontocetes is discussed by Purves (1966).

\section{DISCUSSION}

As stated, the purpose of this paper was to point out the homology of the various structures of the respiratory tract of the Physeteridae with those of other odontocetes. We consider that this is necessary in order to arrive at anything like a correct interpretation of the function of the various parts. We either have to believe in this general assumption or accept the idea that homologous structures can have entirely different functions between families, genera or even species throughout the suborder.

In recent years, a number of hypotheses have been advanced by zoologists and physiologists concerning the mode of hearing and phonation in cetaceans in relationship to the under water echolocation or sonar. It is apparent from the literature that most of these hypotheses have been arrived at from the study of small cetaceans in dolphinaria and more particularly of Tursiops truncatus (Montagu, 1821).

One of these hypotheses that is relevant to the subject of this paper is that all sounds produced by cetaceans are generated at the lateral extremities of the nasal plugs with the accessory air sacs playing an important role in this function (Evans et al., 1964; Norris, 1964).

We have seen that in the Physeteridae the nasal plugs are strongly modified to form an integral part of the lumen of the nares and are in no way suitable for sound production. Some credence may be given to this hypothesis in respect of the "whistles" produced by the majority of odonto- 
cetes since the Physeteridae and Platanistidae which do not possess accessory air sacs have not been observed to produce whistles.

The general asymmetry and low level of muscular control of the nasal plugs make them quite unsuitable for producing the accurate, variablefrequency, multi-beamed sound pulses that are so essential for underwater sonar.

Another hypothesis is that the front of the skull acts as a "parabolic mirror" for the reflection of sounds generated by the nasal plugs and that the melon, because of its bulbous shape, forms an adipose "acoustic lens" for the production of narrow beams of sound.

Apart from the fact that no cetacean skull resembles a parabolic mirror, which is a very precise piece of engineering, there are many species of odontocetes in which the front of the skull is actually convex as in Pontoporia, Monodon, Beluga and young specimens of Grampus. In addition the degree of concavity of the skull is a function of age, becoming greater with the development of the supraoccipital crest.

It has been observed that in Physeter the melon is rudimentary and that in the Platanistidae (Schenkkan, 1972) is not adipose but consists of a mass of fibrous tissue that represents a degenerate form of the maxillolabialis muscle. The adipose tissue found in the melon of other odontocetes represents a later stage in the degeneration of this muscle. Notwithstanding this, all odontocetes are known to produce orientated beams of sound.

Norris (1964), Wood (1964) and Caldwell et al. (1966) have drawn attention to the "museau de singe" in the Physeteridae as a possible sound generator.

Apart from its generally low level of muscular control and dextrad position the "museau de singe" if acting as a sound generator, would be very expensive in its use of air since it acts as a unidirectional valve leading to the vestibular air sac, which in turn communicates with the exterior. Any air which passed through this valve under water would be irrevocably lost so that a very large reservoir of air would be required for a lengthy submergence.

Because of the relevance to the rest of this discussion it is convenient to state at this stage our interpretation of the sonar activity applying the homologue principle. In common with terrestrial mammals all cetaceans have a well de- veloped larynx and we believe that in common with the former, most of the sounds are generated by this organ. It is subject to a high degree of muscular control, not only by its own intrinsic and extrinsic muscles but by the palatopharyngeal muscles in addition. In the production of "sonic beams" we believe that use is made of interference phenomena as in man-made mechanical devices for this purpose. It is significant that no instrument resembling an "acoustic lens" has yet been invented. The production of beamed sound fields has been dealt with by Purves (1966). Of course a large reservoir of air is required for the proper functioning of the larynx at high hydrostatic pressure and we believe that such is the main function of the non-respiratory cavities in the nasal tract of the Physeteridae.

Recently, an ingenious hypothesis for the function of the spermaceti organ in Physeter has been published by Clarke (1970). He claims that neutral buoyancy can be maintained at great depth by cooling the spermaceti oil thus increasing its density to adjust to the increased density of sea water at this depth. The cooling process takes place by vasodilation and by inhalation of cold sea water into the right naris.

Applying the homology principle to Kogia we found that the spermaceti organ was so small as to constitute only a very small fraction of the total weight of the head much less that of the body and even if we included the weight of the adipose cushion referred to above the reduction of density would be insignificant. We therefore concluded that at least in Kogia the spermaceti organ could not serve a hydrostatic function with respect to the weight of the body.

It must be noted that all the above hypotheses have been arrived at with very little reference to the detailed anatomy of the head so it has been decided in this discussion to attempt to arrive at the function of the upper respiratory tract by a study of the mechanical effect of its various parts. For this purpose it will be convenient to divide the respiratory cycle into (a) a hypothetical resting phase (b) a breathing or "loading up" phase (c) a diving phase and (d) a surface recovery phase.

\section{The hypothetical resting phase}

If the head is just submerged with all the facial muscles relaxed, the blowhole will be closed by its own elasticity, as will also the "museau de 
singe". The left naris will be occluded by the special configuration of its ventral wall or "nasal plug". For reasons which will be stated later, there will be a residue of air in the right naris, nasofrontal and right vestibular sacs.

\section{The "loading up" phase}

When the maxillonasalis and maxillolabialis muscles are contracted the left naris will be dilated in both genera by traction on the nasal plug and dorsal wall of the naris. The blowhole will also be opened and fresh air will be inhaled by expansion of the thorax. Now it is wel known that the glottis in both Kogia and Physeter is asymmetrically orientated towards the left and that during contraction of the pharynx is drawn towards the left posterior naris. Thus perhaps the total ventilation of the lungs takes place through the left naris. The unidirectional valvelike structure of the vestibular opening of the right naris would preclude the entry of air by this route.

Contraction of the right maxillonasalis and maxillolabialis muscles opens the "museau de singe" but due to the presence of the spermaceti organ in both genera and the fatty cushion in Kogia the same contraction compresses the nasofrontal sac, the right naris and vestibular sac in sequence. The right nasopalatine plug (fig. 11) and hydrostatic pressure prevent the residual air referred to above from passing backwards and it is squeezed out through the blowhole. The "loading up" process wil occur many times before a deep dive and it is possible that inhalation and exhalation takes place entirely through the left naris.

\section{The diving phase}

At the commencement of the dive the nasal muscle complex will be relaxed and the left naris occluded by the long powerful left nasal plug. The blowhole and "museau de singe" will also be closed and in these circumstances negative pressure will be developed in the right naris due to the buoyancy of the spermaceti organ and of the adipose cushion in Kogia. In Physeter this negative pressure will be produced as lift by the spermaceti organ on the dorsal wall of the right naris, the ventral wall being anchored by powerful collagen fibres passing through the junk (see direction of arrows in figs. 9 and 12). In Physeter this pressure difference can be calculated.
A conservative estimate of the amount of spermaceti in the spermaceti organ of an average adult sperm whale is 300 litres and its specific gravity at $33.5^{\circ} \mathrm{C}$ is 0.8585 . The specific gravity of sea water at $22.3^{\circ} \mathrm{C}$ is 1.0245 at the surface. The weight difference between the equivalent volumes is therefore $(300 \times 1.0245)-(300 \times 0.8585)=50 \mathrm{~kg}$. Owing to the lateral compression of the anterior part of the nares and the valvular structure of the "museau de singe" water would not enter to fill the vacuum caused by this weight difference and the total pressure difference would act as a suction force at the rigid nasopalatine canal which has an approximate area of 2500 sq.mm. The negative pressure at this canal would therefore be about 2 atmospheres.

In Kogia where the amount of adipose cushion and spermaceti organ is about 1 litre, the negative pressure at the right nasopalatine canal, with an approximate area of 50 sq.mm, will be about $1 / 3$ atmosphere. This negative pressure would be sufficient to produce gradual evacuation of the lungs prior to a dive, the residual thoracic air then being shared by the trachea, larynx, and the right nasal air cavities.

Needless to say the air in the right nasal complex would be subject to considerable changes in volume and position due to hydrostatic pressure and swimming attitude. During the head-down attitude and at extreme hydrostatic pressure, all the air would be squeezed into the nasofrontal sac with its rigid posterior wall and elastic anterior wall. Similarly during the head-up attitude and reduced hydrostatic pressure the expanded gas would tend to move forward into the more anterior chambers. This periodical change in the centre of buoyancy of the head may have some hydrodynamic importance in Physeter but rather less in Kogia with its relatively small head.

It would seem that the right vestibular sac in Physeter and the anterior lobe of the right vestibular sac in Kogia would be of great importance for preventing the massive escape of air during the head-up attitude. It will be recalled that the exit of the vestibule is a narrow, membranous slit. in Kogia and in Physeter it is no more than the diameter of two fingers. In Physeter gaseous pressure would build up in the vestibular sac and press against the "museau de singe" and the laterally compressed anterior extremity of the right naris until back pressure due to frictional retardation of the escaping gas was at equilibrium with 
pressure from below. Similarly inflation of the anterior lobe of the vestibular sac in Kogia would cause pressure against the vestibule and the membranous exit to the main vestibular sac with the same result of preventing the gross escape of gas.

The main difference in respiratory function between Kogia and Physeter can be seen in the method of storing the residual thoracic air. In Kogia at moderate pressures, the main reservoir is above the "museau de singe" in the right vestibular sac whilst in Physeter it is below the "museau de singe" in the right naris. In Kogia this thoracic gas would pass at first through the right naris and "museau de singe" into the main part of the right vestibular sac, being assisted by the neg. ative pressure given by the buoyancy of the adipose cushion above the exit of the "museau de singe". This gas would then pass through the peripheral diverticula into the air sac complex above the adipose cushion described in the text. At this stage the adipose cushion would lose its buoyancy and descend over the "museau de singe".

During a head-down dive, the compressed gas would eventually be squeezed into the nasofrontal sac as in Physeter but in so doing would have to pass backwards through the "museau de singe". It is extremely interesting therefore that there is a means of opening the narial part of this organ without interfering in any way with normal muscular systems. The slip of maxillonasalis muscle "borrowed" from the left nasal complex (fig. 5), could be used for this purpose if its individual contraction were possible. It may be stated that this arrangement is unique amongst the Cetacea and perhaps throughout the Mammalia.

There would appear to be no mechanism for allowing sea water to enter the nares as Clarke (1970) postulates and it seems to be a common misconception that water will enter any tube that is inverted into it. A rigid-walled open tube will allow this to happen but a closed tube will allow entry of water only insofar as the compressibility of the enclosed gas will allow. A very softwalled, closed, flattened tube will not allow water to enter since the pressure on its side walls is equal to that on its entrance and results in collapse of the lumen. Nor can we accept that vasodilation is used to cool the spermaceti organ at high pressure. Since the head is not a closed circuit with respect to the blood circulation, vasodilation would result in reduction of the entire body temperature and not just of the head.
In fact, vasoconstriction is more likely to occur at high pressure for the following reasons. All the uppernarial muscle systems, air sacs, adipose tissues and external skin are supplied by branches of external maxillary artery after its passage through the antorbital foramen. Before entering the foramen, the artery - which is a continuation of the external carotid - gives off a large pterygoid artery which in turn, breaks up into a mass of smaller arteries, the pterygoid plexus. The main function of this plexus is to supply the pterygoid venous plexus which lines the vast pterygoid air sinuses that are extensions of the cavity of the middle ear. As the hydrostatic pressure rises, the air in the pterygoid sinuses is squeezed into the rigid tympanic bulla, but the space evacuated must be filled by injection of blood into the pterygoid venous plexus. This requires a relatively enormous amount of blood and the excess can only be obtained by restriction of the amount reaching the upper narial structures which are in a state of rest. It is well known that there is a marked diving bradycardia at depth which would further restrict the blood supply. Cooling of the head and spermaceti organ must certainly occur, but this probably takes place through normal heat radiation and restriction of the blood supply.

There is another good reason why the blood supply to the upper narial systems should be restricted. Since the gas retained in the right nasal cavities is residual thoracic air, it is likely to be composed predominantly of carbon dioxide and nitrogen with the latter in excess. Any nitrogen which passes by gaseous diffusion through the walls of the nasal cavities will be taken up by the adipose tissue before entering the blood stream since adipose tissue will dissolve six times as much nitrogen at any hydrostatic pressure than an equivalent volume of blood.

The fat is unlikely to become saturated except over a very long period. Even when the full blood supply is restored during the ascent of the animal, the negative pressure in the right naris will ensure that any dissolved nitrogen will pass out through the walls of the naris rather than enter the main blood stream.

It is an interesting fact that wherever air cavities in cetaceans are subjected to prolonged periods of high pressure they are always contiguous with large fat depots e.g. the spermaceti organ and adipose cushions in Kogia, the spermaceti organ in Physeter and the inframandibular fatty bodies 
associated with the pterygoid air sacs in both species.

So far, we have not considered why it should be necessary to retain an air reservoir in the right narial complex of the Physeteridae. Both Kogia and Physeter are known to produce echolocation sound pulses (Worthington \& Schevill, 1957; Caldwejl et al., 1966) and we believe these to be generated by the epiglottic spout of the larynx and not by the "museau de singe" as has been asserted.

According to Clarke (loc. cit.), asdic records provide good evidence that sperm whales not infrequently dive to in excess of $1000 \mathrm{~m}$ off Durban, whereas Heezen (1957) states that they appear to be able to dive to at least $1500 \mathrm{~m}$. If we accept Clarke's larger figure of 1000 litres as being the lung capacity of the sperm whale then all this air if retained in right narial complex would be reduced to a volume of approximately 5 litres at $1000 \mathrm{~m}$ depth.

It follows that the entire residual air must eventually be squeezed into the right postriarial cavity. Some of this air could then be drawn into the larynx by contraction of the thyrohyoid, omohyoid and sternohyoid muscles for the production of sonar clicks when these muscles were relaxed.

These oscillations would be transmitted to the bones of the rostrum by the paired palatopharyngeal muscles (fig. 11: MPP) as a double source to produce sound fields in front of the animal, differentiated in width and range. Whilst cruising and food finding at great depth there would be virtually no air in the right narial complex and therefore these cavities would be of no value in hydrostatic regulation. It is conceivable therefore that the increased density of the water is compensated for by the cooling of the spermaceti as Clarke states, although not in the manner he suggests.

\section{The recovery phase}

It is perhaps during the recovery phase that air in the right narial complex would be most useful. The thorax is probably fully collapsed before diving as suggested by Clarke and for mechanical reasons postulated by us and would take no part in the ascent. The head would normally be topmost whilst surfacing and the expanded gas would pass upward into the right nares assisted by the suction force induced by the buoyancy of the spermaceti organ and adipose cushion in Kogia and the spermaceti organ alone in Physeter. This gas would eventually reach the right vestibular sac in Kogia and the anterior part of the right naris in Physeter thus increasing the buoyancy of the head and assisting the swimming motion.

Meanwhile the blood circulation would be restored by expansion of the pterygoid sinuses and the lessening of bradycardia. At the surface all the nasal muscles would contract. Dilating the blowhole and "museau de singe" and all the air in the right narial complex would be squeezed out to form the visible blow. At the end of this cycle loading up would occur through the left naris alone.

Histological examination of the numerous papillae in the nasofrontal sac of Kogia shows that no secretory function can be assigned to these structures. In this small cetacean, in the resting state the interval between the anterior and posterior walls is very narrow and its communication with the right naris small and anteroposteriorly constricted. It is possible that these small papillae act as hydraulic buffers to prevent the complete vacuum apposition and adhesion of the walls of the nasofrontal sac during a deep dive.

\section{ACKNOWLEDGEMENTS}

Grateful acknowledgements are due to various individuals who have helped us in the accumulation of material for this research, and to others who have extended facilities for carrying out the dissections.

To Mr. Frank D. Robson (New Zealand) for collecting and dispatching to the Institute of Taxonomic Zoology of the University of Amsterdam two deepfrozen heads of Kogia breviceps.

To Dr. P. B. Best, Division of Sea Fisheries, Cape Town South Africa for the deepfrozen head of Kogia simus and to the British Museum (Natural History) for the preserved head of a foetal Sperm Whale, Physeter macrocephalus.

In relation to research facilities we would like to thank Drs. P. J. H. van Bree for making available to us the specimens of Kogia breviceps referred to above and Prof. Dr. G. Barendrecht, Director of the Zoological Laboratory of the University of Amsterdam for use of the prosectorium.

We wish especially to thank Dr. W. L. van Utrecht for kind cooperation. Much valuable advice in the production of the drawings was extended by Dr. S. van der Spoel of the Institute of Taxonomic Zoology.

Thanks are also due to the British Museum (Natural History) for the facilities to dissect the heads of Kogia simus and Physeter macrocephalus.

The studies of the first author were made possible by a grant from the Netherlands' Organization for the Advancement of Pure Research (Z.W.O.) which organization also subsidized some visits to the British Museum (Natural History). For the subventions received he is greatly indebted. 


\section{ABBREVIATIONS}

$\begin{array}{ll}\text { AC } & \text { adipose cushion } \\ \text { BL } & \text { blowhole } \\ \text { C } & \text { case } \\ \text { CLV } & \text { crypts of left vestibular sac } \\ \text { G } & \text { glottis } \\ \text { JU } & \text { junk } \\ \text { LN } & \text { left naris } \\ \text { MCN } & \text { compressor naris muscle } \\ \text { MES } & \text { mesethmoid } \\ \text { ML } & \text { melon } \\ \text { MNP } & \text { nasal plug muscle } \\ \text { MPP } & \text { palatopharyngeal muscle } \\ \text { MS } & \text { "museau de singe" } \\ \text { MX } & \text { maxillary bone } \\ \text { MXL } & \text { maxillolabialis muscle }\end{array}$

$\begin{array}{ll}\text { MXN } & \text { maxillonasalis muscle } \\ \text { NP } & \text { nasal plug } \\ \text { NPC } & \text { nasopalatine canal } \\ \text { ORV } & \text { orifice of right vestibular sac } \\ \text { PM } & \text { premaxillary bone } \\ \text { PPS } & \text { palatopharyngeal sphincter } \\ \text { RN } & \text { right naris } \\ \text { SA } & \text { accessory sac } \\ \text { SN } & \text { nasofrontal sac } \\ \text { SO } & \text { spermaceti organ } \\ \text { SPM } & \text { premaxillary sac } \\ \text { SV } & \text { vestibular sac } \\ \text { SVR } & \text { right vestibular sac } \\ \text { TON } & \text { tongue } \\ \text { V } & \text { vestibule }\end{array}$

\section{REFERENCES}

BedDard, F. E., 1915. Contributions to the knowledge of the anatomy of the Sperm Whale (Physeter macrocephalus) based upon the examination of a young Foetus. Ann. Durban Mus., 1 (2) : 107-124, pl. VIII, 9 text figs.

-, 1919. Further contributions to the anatomy of the Sperm Whale (Physeter macrocephalus) based upon an examination of two additional foetus. Ann. Durban Mus., 2 (4) : 129-148, pl. XXIII, 13 text figs.

Benham, W. BlaXiland, 1901. On the anatomy of Cogia breviceps. Proc. zool. Soc. Lond., 1901: 107-134, pls. VIII-XI, text figs. 7-8.

Caldwell, D. K., J. H. Prescott \& M. C. Caldwell, 1966. Production of pulsed sounds by the Pigmy Sperm Whale Kogia breviceps. Bull. Sth. Calif. Acad. Sci., 65 (4) : 245-248.

Clarke, M. R., 1970. Function of the spermaceti organ of the Sperm Whale. Nature, Lond., 228 : 873-874.

DANOIS, ED. [LE], 1910. Recherches sur l'anatomie de la tête de Kogia breviceps Blainv. Archs. Zool. exp. gén., 5 (6) : 149-174, pls. V-VIII.

Evans, W. E., W. W. Sutherland \& R. G. Bell, 1964. The directional characteristics of delphinid sounds. In: W. N. Tavolga ed., Marine bio-acoustics : 353-372. (Pergamon Press, Oxford, London, New York, Paris.)

GrUHL, K., 1911. Beiträge zur Anatomie und Physiologie der Cetaceennase. Jena. Z. Naturw., 47 (3) : 367-414.

HeEzen, B. C., 1957. Whales entanglod in deep-sea cables. Deep Sea Res., 4 : 105-115.

Huber, E., 1934. Anatomical notes on Pinnipedia and Cetacea. Publs. Carnegie Instn., 447: 107-135, 12 text figs.

HuNTER, J., 1787. Observations on the structure and oeconomy of whales. Phil. Trans. R. Soc. 77 : 1-371.

KelloGG, R., 1928. Adaption of structure to function in whales. Cooperation in Research. Carnegie Inst. Washington Publ., 501 : 649-682.

- , 1928. The history of whales-their adaption to life in the water. Q. Rev. Biol., 3 (1) : 29-76, 11 figs.

,- 1928 . The history of whales-their adaption to life in the water. Q. Rev. Biol., 3 (2) : $174-208,24$ figs.
KernaN, J. D. JR. \& H. von W. Schulte, 1918. Memoranda upon the anatomy of the respiratory tract, foregut, and thoracic viscera of a foetal Kogia breviceps. Bull. Am. Mus. nat. Hist., 38 : 231-267, 16 figs.

LAWrence, B. \& W. E. SChevill, 1956. The functional anatomy of the delphinid nose. Bull. Mus. comp. Zool. Harv., 114 : 103-151.

MiLleR, G. S. JR., 1923. Telescoping of the cetacean skull. Smithson. misc. Coll., 76 (5) : $1-70,8$ pls.

MURIE, J., 1873. On the organization of the Caaing Whale, Globicephalus melas. Trans. zool. Soc. London, 8 : 235-301, pls. XXX-XXXVIII.

NorRIS, K. S., 1964. Some problems of echolocation in cetaceans. - In: W. N. TAvolgA, ed., Marine bioacoustics : 317-336. (Pergamon Press, Oxford, London, New York, Paris.)

Pouchet, G. \& H. Beauregard, 1885. Note sur „l'Organe des Spermaceti". C.r. Séanc. Soc. Biol., 2 (8) : 342344.

PuRves, P. E., 1966. Anatomical and experimental observations in the cetacean sonar system. In : $\mathbf{R}$. G. BUSNEL, ed., Systèmes sonars animaux; biologie et bionoque : $197-270$ (Symp. Frascati).

RaVen, H. C. \& W. K. Gregory, 1933. The spermaceti organ and nasal passages of the Sperm Whale (Physeter catodon) and other odontocetes. Am. Mus. Novit., 677 : $1-18,9$ figs.

Rawitz, B., 1900. Die Anatomie des Kehlkopfes und der Nase von Phocaena communis Cuv. Int. Mschr. Anat. Physiol., 17 : 245-354.

SCHENKKAN, E. J., 1971. The occurrence and position of the "connecting sac" in the nasal tract complex of small odontocetes (Mammalia, Cetacea). Beaufortia, 19 (246) : $37-43,3$ figs.

,- 1972 . On the nasal tract complex of Pontoporia blainvillei (Gervais \& d'Orbigny, 1844) (Mammalia, Odontoceti). Invest. Cetacea, 4:83-90.

Tyson, E., 1680. Phocoena, or the anatomy of a porpess, dissected at Gresham College London. Dubl. phil. J., 2 (3) : $48-60$. 
WooD, F. G. JR., 1964. [Remark in general discussion concerning Dreher, J. J. \& W. E. Evans, Cetacean Communication]. In : W. N. TAvolga ed., Marine bio-acoustics : 395-396. (Pergamon Press, Oxford,
London, New York, Paris.)

Worthington, L. V. \& W. E. SChevill, 1957. Underwater sounds heard from Sperm Whales. Nature, Lond., 180 : 291.

Received : 14 November 1972 